\title{
THE ONLINE PBL (PROJECT-BASED LEARNING) EDUCATION SYSTEM USING AI (ARTIFICIAL INTELLIGENCE)
}

\author{
Takao ITO ${ }^{1}$, Mikiko Sode TANAKA ${ }^{2}$, Masako SHIN ${ }^{1}$ and Keisuke MIYAZAKI ${ }^{1}$ \\ ${ }^{1}$ Kanazawa Institute of Technology, Japan \\ ${ }^{2}$ International College of Technology, Japan
}

\begin{abstract}
This paper proposes the project-based learning (PBL) education system which uses Artificial Intelligence (AI) instead of teachers' direct instruction. Kanazawa Institute of Technology (KIT) applies PBL to its design and engineering programme as Project Design (PD) Programme. Students form small groups to discuss real-life problems and sometimes collaborate with local communities. However, in order to prevent COVID-19 infection, students cannot go to school. Instead, e-Syllabus and the web meeting Zoom (videoconferencing software) are used to take lectures at home. Adding to the PBL class implementation experience under the impact of COVID-19 and to the review results of the progress of digital technology, the outline, and the feature of the on-line PBL education system using chatbot and $\mathrm{AI}$ is proposed. Although the system is still under development, some of the components are introduced.
\end{abstract}

Keywords: PBI, Artificial Intelligence (AI), COVID-19, online, e-learning, chatbot, text mining

\section{INTRODUCTION}

The importance of problem-based learning and project-based learning (both abbreviated to PBL) is perceived in engineering education and in addressing the Sustainable Development Goals (SDGs). Kanazawa Institute of Technology (KIT) applies PBL to its design and engineering programme as Project Design Programme (PD). The programme aims to grow up independently minded, actively engaged engineers. PD consists of 5 compulsory courses which are held in 12 departments in all four colleges: College of Engineering, College of Informatics and Human Communication, College of Architecture, and College of Bioscience and Chemistry. The focus of this programme is the use of the design process to solve the problems, and at the same time, to enhance students' innovation skills rather than specific engineering theories. Each project team in each PD course consist of four to six students and sets up their own project theme. That means more than 250 projects are set up in each PD course every year [1]. Students form small groups to discuss real-life problems, find out solution cooperatively and learn practical knowledge through PBL. PBL should be collaborative, constructive, contextual, and self-directed. They sometimes collaborate with local communities [2].

However, in order to prevent COVID-19 infection, the Japanese government issued the state of emergency on the metropolitan area on April 7 and expanded it all over the country on April 16, 2020. The state of emergency lasted about a month until it was completely lifted nationwide in May 25 [3]. Students cannot go to school or take lectures in classrooms. Instead, most universities used the web meeting tools such as Zoom and WebEx for their students to take lectures at home. In KIT, classes started as on-line on April 20. Group discussion in the classroom indispensable for PBL became impossible.

To advance an educational reform, introduction of the digitalized education system and the learning management system (LMS) have been promoted. We dealt with the classes using our LMS, e-Syllabus which were launched in 2016 [4]. However, there were comments in the questionnaires after the classes which described the dissatisfaction to PBL activity. Furthermore, the work loads of on-line PBL to teachers were larger than the usual PBL in the present LMS.

Through the system survey focused on the artificial intelligence (AI) we have recognized that chatbots which combine text-mining technology and AI have come to be utilized in many companies. Chatbots are used increasingly to reply to questions automatically using AI technology. There are many free 
communication and collaboration tools: students use SNS more than e-mail. It is required to utilize the Information and Communication Technology (ICT) further and to improve LMS. The authors are investigating the online PBL education system which uses AI instead of teachers' direct instruction or TA's (Teaching Assistant's) support. We propose the on-line PBL education system using Slack and chatbots with AI.

The rest of the paper is organized as follows. Section 2 elaborates on the experience of the on-line PBL and the results of PD2 which were held in 2020 spring semester. In section 3, we review new digital technologies and trends of application of AI to education fields. Section 4 proposes the new on-line PBL education system which uses chatbot and AI. Although the system is still under the development phase, some of the system components will be introduced.

\section{PD2 COURSES IN COVID-19}

Out of five Project Design Programme (PD) courses PD Introduction and PD2 are held in Spring Semester and PD1 and PDIO are held in Fall Semester. Before 2019 meaning before COVUD-19 pandemic, all courses were carried out in classrooms divided in groups. Sophomores in 2020 took PD1 in classrooms in 2019 and PD2 on-line. They could compare PD course in classrooms and that on-line. First, we explain e-Syllabus System used on-line classes, then we review the results of PD2 courses in COVID-19.

\section{1 e-Syllabus System in KIT}

Since KIT launched the e-Syllabus in 2016, the teachers have been utilizing the e-Syllabus as one of communication tools with students. Some of them have been using the e- Syllabus when carrying out flipped learning and active learning [5].

E-Syllabus is a powerful tool when carrying out flipped learning and active learning. It was used as the main platform of the on-line education under the state of emergency of COVID-19. An example of eSyllabus of a PD2 class is shown in Figure 1.

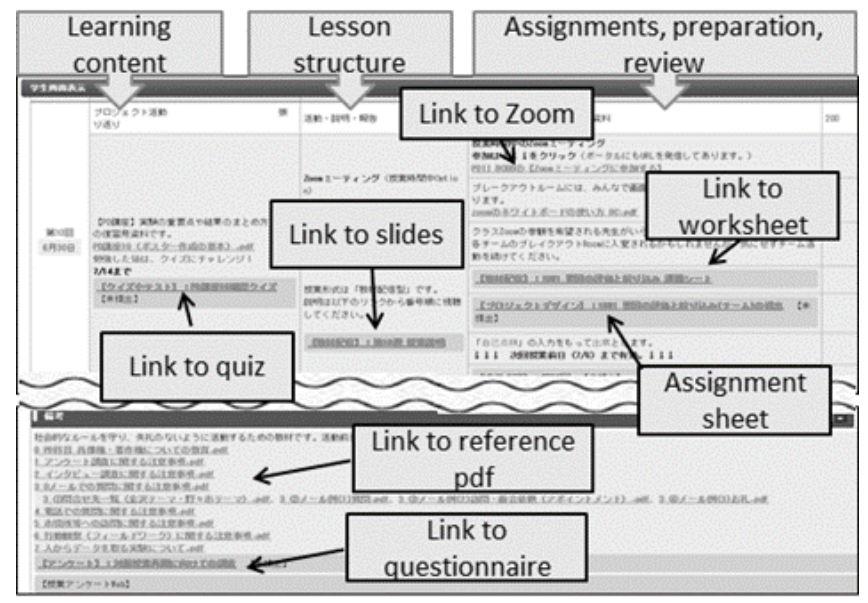

Figure 1. The example of e-Syllabus of a PD2 class

E-Syllabus is displayed, if a student logs in to his page from the portal site, opens his list of courses and click the course. E-Syllabus displays the contents of learning of weekly classes with the guide of learning targets, scholastic evaluation method, and preferred achievement, etc. The teacher in charge can upload preparation teaching materials and worksheets before the class and gives assignments. Students prepare their lessons by e-Syllabus and participate in the Zoom on-line class in the school hour. After an introductory lecture, students are divided in groups and work in Zoom Breakout Rooms. The teacher does the quiz which confirms learning results of the week, receives questions from students or guides discussion by students. He or she can carry out quiz and questionnaires by e-Syllabus in school hours and can confirm degree of comprehension on the scene. Reference materials can be uploaded so that students can use as reference materials during group discussions. 


\subsection{Results of PD2 courses in COVID-19}

At the end of the semester, in order to carry out self-valuation of the degree of achievement of students' study target, the questionnaire survey was carried out using e-Syllabus. The questionnaires were designed to answer the achievement level of study targets by percentage: from $100 \%$ meaning completely well achieved to $0 \%$ meaning not at all. The survey also asked free comments about the online learning.

We compared the questionnaire results of the on-line PD2 class in 2020 with the questionnaire results of the PD2 class carried out in the classroom in 2019. 896 students answered the questionnaires in 2020 and 1,442 students answered in 2019. The number of replies of questionnaires are different because 2020 questionnaires were carried out on-line while 2019 questionnaires were carried out in classrooms. The on-line response rate became lower than that carried out in classrooms.

Although two questionnaires were not the same, some questions were the same. What were compared are the degree of achievement of problem discovery capability, team activity, logical thinking, and the degree of satisfaction of the class. The result is shown in Figure 2. The explanatory note A of the graph indicates $100 \%$ of the degree of achievement or satisfaction, B indicates more than $80 \%$ achievement or satisfactory enough, $\mathrm{C}$ indicates more than $60 \%$ achievement or not enough satisfactory, and D to F indicate less achievement or dissatisfaction.

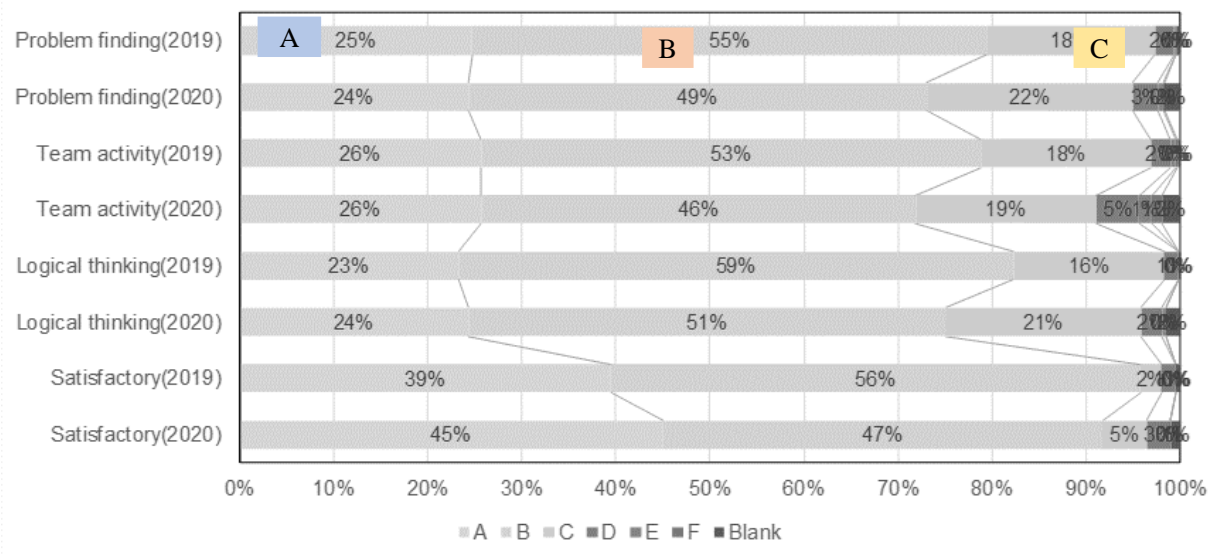

Figure 2. Comparison of questionnaires

For the degree of achievement of problem discovery capability, team activity and logical thinking, the percentage of $\mathrm{A}+\mathrm{B}+\mathrm{C}$ (the total rate of more than $60 \%$ achievement) of 2020 is lower than that of 2019 while the percentage of A ( $100 \%$ achievement) is almost the same. That indicates that whether the class is on-line or in a classroom does not influence the learning results for high performers. The students of the achievement ratio of $80 \%$ or less need suitable instruction at on-line classes. Students did mutual learning by group work in classrooms or after class in 2019. However mutual learning for which students gather became impossible in 2020.

For the satisfactory level, the satisfaction rate is higher in 2020 than that in 2019 while A+B is lower in 2020 than that in 2019. In free descriptions, while there are comments affirmative about the on-line class as it is easier to review the learning contents later, there are also comments that it is hard to do group activity on-line. It is hard to cause the motivation of low students of greediness for learning by on-line learning. There are some comments that there are many assignments, some of them are difficult and it is hard to do them online. Some students need easy to understand explanation to assignments. There are also comments that it is hard to question the teacher in the on-line class.

\section{DIGITAL TECHNOLOGIES IN EDUCATION}

The education / learning methods are changing with progress in ICT. The Education Reform Committee of Japan's Ministry of Education, Culture, Sports, Science and Technology (MEXT) considered the innovation of the education corresponding to progress of technology. The Committee has proposed the following to the Cabinet; innovation for collaborative and interactive lectures utilizing group studies and ICT, as well as cooperation between schools and families/communities should be promoted, along with the implementation of the new Course of Study [6]. 
Furthermore, the trial which uses AI and chatbot for education is studied. The application of AI has accomplished remarkable development recently and attracts attention as the 3rd boom. There are many articles published about AI applications in education. We can consult much literature on websites.

\subsection{Intelligent tutoring system}

Intelligent tutoring system (ITS) is an outgrowth of the computer-aided instruction (CAI) [7]. ITS analyses students' responses to specific questions and changes learning contents based on the answers. For example, Media5 corporation provides learning materials for high school students which use AI to support best learning methods for each student [8]. Students answer some questions before learning video materials, and AI navigates best learning methods to improve their learning scores. It analyses the past problem and creates mock problems. It also manages a student's learning schedule.

\subsection{Text mining}

The second example of the recent application of AI is the text mining. Text mining transforms unstructured text into structured words and extracts meaningful patterns. It can explore and discover new meanings in the text data. Peculiar processing and ICT technology were required for the text mining before. Nowadays there are some commercial based text mining tools available that can be used to analyse voices of customers from surveys or social media. We have used Mieruka-Engine ${ }^{\mathrm{TM}}$ for analysing the free descriptive answers of students who took PD courses. Some results were reported in 2018 [9]. Mieruka-Engine ${ }^{\mathrm{TM}}$ claims as No.1 text mining tool in Japan (Mieruka-Engine ${ }^{\mathrm{TM}}$ is a registered trademark of Plus Alpha Consulting Co., Ltd.) [10].

\subsection{Chatbot}

Another example of application of $\mathrm{AI}$ is the chatbot in question-answering. The chatbot is a software that can chat (converse) through websites or messaging applications. It is like the interaction between humans and robots. Robin Singh wrote an article on Chatbots Magazine in 2018 [11]. In the article he pointed that chatbot with AI technology can be used to teach the students by turning a lecture in a series of messages to make it look like a standardized chat conversation. Areeba Khan announced Chatbot makers utilize artificial intelligence and the latest conversational design to create bots that can communicate with students as well as teach them [12].

For the purpose of the increase in efficiency of corresponding to questions from customers (or students), the automatic inquiry systems which utilized AI are commercialized. They are used not only for business use but for education. Kindai University in Japan has introduced "Virtual TA for Slack" using manaBrain ${ }^{\circledR}$ (manaBrain ${ }^{\circledR}$ is the registered trademark of SCSK Corporation) [13].

\subsection{Speech recognition and image recognition}

As the use of AI, speech recognition and image recognition are performed widely. Speech recognition is used for the translation machine. Image recognition is the technology indispensable to development of automatic driving. These AI technologies can also be used for the education area.

\section{ON-LINE PBL EDUCATION SYSTEM}

Taking advantage of the rich instructional materials, students' deliverables, and questionnaire results of KIT PBL courses, the authors are investigating the online PBL education system which uses AI instead of instructors. Based on the on-line PD2 experience and the survey of AI systems, we propose the online PBL education system which combines PBL and digitalized learning. In PBL education, the role of the teacher as a facilitator is important and the bidirectional communication between the teacher and students is needed. There are many subjects to be solved in the systems configuration: how to prepare teaching materials, teacher know-how, and an ICT system and how to utilize AI in the system.

The composition of the education system under plan is shown in Figure 3. Students access to the digital platform e-Syllabus and work on their project team database (DB). The AI engine communicates with students on the digital platform and acts as the facilitator. Text mining and chatbot serve as main components of the AI engine. It uses the course materials and know-how database as a reference to answer students' questions. Some components are already prepared and there are some programmes and linkages under investigation. 


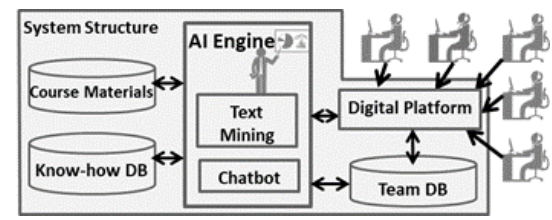

Figure 3. Composition of the on-line PBL education system

\subsection{Digital Platform}

The e-Syllabus system is used as the LMS platform in KIT. As mentioned in 2.1, teachers and students use it as on-line course tools. Students can access Zoom Breakout Rooms and chatbot via e-Syllabus. As students get used and are familiar with communication by social networking service (SNS), they perform group activities and group discussion there. A "Channel" can be set up for each project and project members communicate and work in the channel. All of the conversation and produced data can be recorded as a searchable team data.

\subsection{Course Materials and Know-how Database}

The AI engine accesses course materials and the know-how database and instruct students. More than 6,500 reports of the four Project Design Programme courses from 2012 to 2018 are stored in the database: about 1,500 PD Introduction experiment reports, 1,700 PD1 design reports, 2,000 PD2 implementation documents and 1,400 PDIO project repots. The students taking PD courses can search the documents related to their theme from the database. There is also the database which teachers prepared the principles and laws of physics and chemistry. Teachers' instruction materials including PowerPoint class slides are also on the e-Syllabus and the web server as shown in 2.1.

\subsection{Al Engine}

The mascot character of KIT, Drever, acts as the PBL teacher using the AI engine as shown in Figure 4. It can reduce teachers' workload of replying to students' question and facilitates project activities instead of teachers. During on-line PBL classes students ask many questions by mail or chat not only the class hours but even midnight when students do their homework. Some students hesitate questioning teachers even during class hours. Instead, students can ask Drever questions through the digital platform. Although it is necessary to prepare the questions and answer (Q\&A) data beforehand, Drever answers questions and accumulates what are asked from students and feedbacks to answers. The teacher in charge analyses Q\&A log data and modifies Q\&A data. As the AI engine of Q\&A chatbot, manaBrain ${ }^{\circledR}$ can be used.

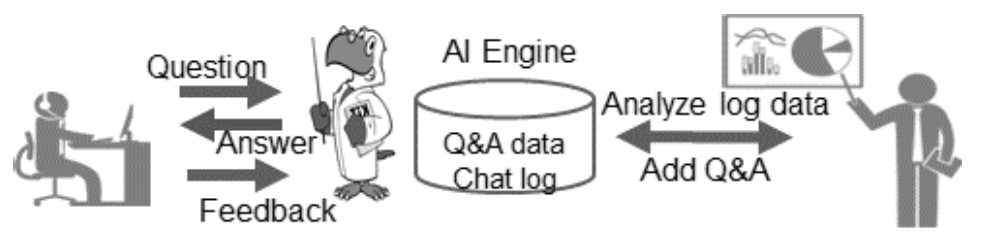

Figure 4. Drever and the Al chatbot for Q\&A

The AI also analyses students' documents and the participating situation of the students to group activities using speech recognition and warns the low students of willingness to learn. It behaves like the facilitator who takes charge of the projects.

\subsection{Pros and Cons of the System}

It is the key to the system to prepare enough $\mathrm{Q} \& \mathrm{~A}$ data. Once the questions and answer $(\mathrm{Q} \& \mathrm{~A})$ data are adequately prepared, students can perform project activities on-line. They can chat using SNS and Drever facilitates anytime. Teachers do not need to work late in order to reply to students' questions. Teachers' roles change to analyse students' activities and to give feedback through Drever.

However as mentioned in 2.2, it is hard to cause the motivation for learning by on-line learning. The mechanism of cultivating students' mutual learning is required. Occasionally idle talk with teachers may be effective for motivating students. It will take some time for AI to do idle talk with students. 


\section{CONCLUSIONS}

PBL classes were carried out on-line using e-Syllabus during the state of emergency caused by COVID19 and continued through the spring semester in 2020. Some problems were revealed from the questionnaire survey at the end of the semester. Mutual learning for which students gather became impossible and it was hard to cause the motivation of low students of greediness for learning. While there are comments affirmative about the on-line class, there are also comments that it is hard to do group activities on-line.

From the survey of digitization and development of AI, we propose the on-line PBL education system, which consists of the digital platform, the team database, the AI engine, the course materials, and knowhow database. As students get used and are familiar with communication by SNS, adding to our eSyllabus system, the on-line PBL education system using Slack and chatbot is proposed. Text mining and chatbot serve as main components of AI engine. There are several tools which can be available as the AI engine, and the on-line PBL education system can be constructed by combining them. The PBL teacher using AI can be realized to support PBL instead of teachers' direct instruction. The system is still in the development phase. Furthermore, many works are required including the valuation method of project activities besides chatbot programme creation.

\section{REFERENCES}

[1] Ito T., Shin M., Miyazaki K., Iwata S., and Sentoku E. The Effects of Spiral Educational Method through PBL: KIT Project Design Programme. In Proc. of the 43rd Annual SEFI Conference, 2015.

[2] Ito T., Shin M., Miyazaki K., Iwata S., and Sentoku E. The Project Design Education Collaborating with City Governments and Communities. In Proc. of the 18th International Conference on Engineering \& Product Design Education, 2016.

[3] Cabinet Secretariat. The Basic Policies. Available: https://corona.go.jp/en/news/news_20200510_76.html [Accessed on 2021, 19 February], (2020) 25 May.

[4] KIT. Message from the President. Available: https://www.kanazawait.ac.jp/ekit/about/strategy/index.html [Accessed on 2021, 19 February].

[5] Ito T., Ishii K., Nishi M., Shin M., and Miyazaki K. Comparison of the effects of the integrated learning environments between the social science and the mathematics. In Proc. of the SEFI 47th Annual Conference, Budapest, September 2019, pp.550-558.

[6] MEXT. The Second Basic Plan for the Promotion of Education. Available: https://www.mext.go.jp/en/policy/education/lawandplan/title01/detail01/1373796.htm [Accessed on 2021, 19 February], (2013) 14 June.

[7] Freedman R. What is an Intelligent Tutoring System? In Intelligence 11(3), Fall 2000.

[8] Media5. Premier6. Available: http://www.media-5.co.jp/pr6/study/index.html (Japanese) [Accessed on 2021, 19 February]

[9] Ito T., Shin M., Miyazaki K. and Matsumoto K. Data and Text Mining for Analysing the Pedagogical Effects of Diverse Design Projects. In Proc. of the 20th International Conference on Engineering \& Product Design Education, London, September 2018, p.18.

[10] Plus Alpha Consulting Co. Ltd. Mieruka-Engine. Available: https://www.mieruka-engine.com/ (Japanese) [Accessed on 2021, 19 February]

[11] Singh R. AI, and Chatbots in Education; What Does The Future Hold? Available: https://chatbotsmagazine.com/ai-and-chatbots-in-education-what-does-the-futurehold9772f5c13960?gi=79ad3101f58e [Accessed on 2021, 19 February] , (2018) 3 May.

[12] Khan A. How Education Industry Is Being Improved By AI Chatbots? Available: https://medium.com/botsify/how-is-education-industry-being-improved-by-ai-chatbots4a1be093cdae [Accessed on 2021, 19 February], (2019) 6 May.

[13] Otani M., et. Al. V-TA: Dialogue System for Practical Training on Software Development. In Proc. of the 33rd Annual Conference of the Japanese Society for Artificial Intelligence, Niigata, June 2019 (Japanese). 